\section{DYSDG New Technologies} 2015
A LOW COST SYSTEM FOR THE PREDIAGNOSIS OF THE HUMAN TREMOR

\title{
UN SISTEMA DE BAJO COSTE PARA LA AYUDA AL PREDIAGNOSTICO DEL TEMBLOR HUMANO
}

María Luisa Pertegal-Felices ${ }^{1}$, Doctora en Psicopedagogía

Antonio Jimeno-Morenilla ${ }^{2 *}$, Doctor en Ingeniería Informática

Francisco A. Pujol2, Doctor en Ingeniería Informática

Cristian Hernandez Salvador² , Ingeniero Informático

Antonio Martínez-Alvarez², Doctor en Ingeniería Electrónica

1 Developmental and Instructional Psychology Departament,/ Departamento de Psicología Evolutiva y Didáctica

2 Computer Technology Department / Departamento de Tecnología Informática y Computación

Universidad de Alicante, Campus de San Vicente s/n, 03690 San Vicente del Raspeig (Alicante)

* imeno@dtic.ua.es, telf. +34 965903400 Ext. 2453

\section{Recibido: $\quad$-- Aceptado: - DOI: 10.(A cumplimentar por el Editor)}

\section{A LOW COST SYSTEM FOR THE PREDIAGNOSIS OF THE HUMAN TREMOR}

\section{ABSTRACT:}

Human tremor can be defined as a somewhat rhythmic and quick movement of one or more body parts. In some people, it is a symptom of a neurological disorder. From the

mathematical point of view, human tremor can be defined as a weighted contribution of different sinusoidal signals which causes oscillations of some parts of the body. This sinusoidal is repeated over time, but its amplitude and frequency change slowly. This is why amplitude and frequency are considered important factors in the tremor characterization, and thus for its diagnosis. In this paper, a tool for the prediagnosis of the human tremor is presented. This tool uses a low cost device $(<\$ 40)$ and allows to compute the main factors of the human tremor accurately. Real cases have been tested using the algorithms developed in this investigation. The patients suffered from different tremor severities, and the components of amplitude and frequency were computed using a series of tests. These additional measures will help the experts to make better diagnoses allowing them to focus on specific stages of the test or get an overview of these tests. From the experimental, we stated that not all tests are valid for every patient to give a diagnosis. Guided by years of experience, the expert will decide which test or set of tests are the most appropriate for a patient.

Keywords: human tremor, Wiimote® device, filtering techniques, prediagnosis tool.

\section{RESUMEN:}

El temblor humano puede definirse como un movimiento rápido y, en cierta manera, rítmico de una o más partes del cuerpo. En algunas personas, este movimiento puede ser un síntoma de alguna alteración a nivel neurológico. Desde el punto de vista matemático, el temblor humano puede ser definido como una suma ponderada de diferentes señales sinusoidales que causan oscilaciones de algunas partes del cuerpo. Esta sinusoide se repite en el tiempo pero su amplitud y frecuencia cambian lentamente. Por esta razón, la amplitud y la frecuencia son consideradas factores importantes en la clasificación del temblor y por tanto útiles en su diagnóstico. En este artículo, se presenta una herramienta de ayuda al diagnóstico del temblor humano. Esta herramienta usa un dispositivo hardware de bajo coste $(<\$ 40)$ y permite calcular las principales componentes de esta sinusoide asociada al temblor de una manera precisa. Como casos de estudio se presentan su aplicación a dos casos reales para probar la bondad de los algoritmos desarrollados. Los casos muestran pacientes que sufrían temblores con distinta severidad y que han realizado una serie de tests con el dispositivo para que el sistema calculara las principales componentes del temblor. Estas medidas aportadas por el sistema ayudarían en un futuro a los expertos a tomar decisiones más precisas permitiéndoles centrarse en determinadas fases del test o la realización de tests más específicos para evaluar mejor las características propias del temblor del paciente. De la experimentación realizada podemos afirmar que no todos los tests son válidos para el diagnóstico para todos los pacientes. Será finalmente la experiencia del profesional el que decidirá finalmente qué test 0 conjunto de tests son los más apropiados para cada paciente.

Palabras clave: temblor humano, dispositivo Wiimote $₫$, técnicas de filtrado, herramienta de prediagnóstico. 


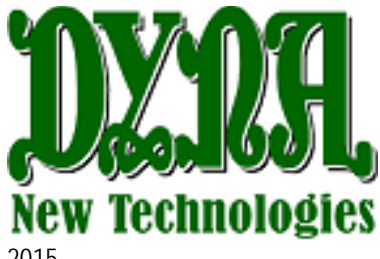

2015
A LOW COST SYSTEM FOR THE PREDIAGNOSIS OF THE HUMAN

TREMOR

María Luisa Pertegal-Felices, Antonio Jimeno-Morenilla, Francisco A. PujolLópez, Cristian Hernandez, Antonio Martínez-Alvarez
Tecnología Informática

Sensores

\section{1.- INTRODUCTION}

The human tremor can be defined as a wave, nearly sinusoidal, causing oscillations in certain parts of the body [1, 2]. Other authors define it as a quick, sharp movement of a particular part of the body, caused by a symptom or a disease [3]. It can also be defined as a rhythmic and sinusoidal [4] involuntary movement.

Although there are several definitions, most authors characterize the tremor by a sinusoidal, aperiodic signal repeated over a long period of time, whose frequency and amplitude vary slowly $[2,4,5]$. That is the reason why the frequency and the amplitude of this signal are considered to provide substantial information to describe the trembling motion and, as a consequence, to classify tremor [2].

In fact, the amplitude and frequency of tremor are the first parameters evaluated by a doctor to diagnose and understand the severity of the disease. Specifically, the frequency parameter is the most crucial in order to know what type of tremor the patient has. Moreover, the amplitude allows assessing the impact of the disease. For example, many people cannot work when the tremor amplitude is high.

\section{1.- Tremor classification}

There are different classifications of human tremor according to the different factors involved. One way to classify it is to divide it into two categories based on the reason that causes the tremor. In this case we can find the pathological and the physiological tremor. The physiological tremor is inherent to human behavior, while the pathological tremor is caused by external factors such as disease, some chemicals or other causes [6].

Tremor can be also classified according to its behavior. Thus, tremor may occur when a person is doing some activities or when he is resting [7]. This way, the tremor can be divided into three types: postural, kinetic or intentional. Postural tremor happens when the patient tries to maintain a body position, for example when the patient has his arms extended. Kinetic tremor occurs when patients need accuracy to perform a task, for example, they want to draw different shapes using one of their fingers. Finally, intentional tremor is the one that appears when the task requires a specific purpose, such as drawing, speaking and standing in a classroom.

Other classifications are made based on the most common diseases that cause tremor. Consequently, Parkinsonian tremor, essential tremor and cerebellar tremor fall inside this category.

The Parkinsonian tremor [2, 8] occurs when the patient is at rest. It is a slow, degenerative disease of the central nervous system studied by Dr. James Parkinson in 1817 and it is very common in humans. The effects of this disease increases with age. If patients make a voluntary movement, then the tremor stops for a moment, but when the movement ends, the tremor continues with a slight to moderate intensity. Some previous works have estimated that the frequency of this tremor is in the range from 3.5 to $6 \mathrm{~Hz}$ [8], while others consider it to be between $4 \mathrm{and} 6 \mathrm{~Hz}$ [7].

Essential tremor is a disease that mainly affects the adult population from 40 years old. It is 20 times more common than Parkinsonian tremor [9]. This tremor is an example of pathological tremor. The disease is inherited in 50\% of the cases analyzed [8]. The tremor appears as a postural and a kinetic tremor and it principally affects the hands. The affected areas of the brain belong to the cortex. In this case, some works consider that the frequency range of this tremor is between 4.5 and $8 \mathrm{~Hz}$ [8], while other authors establish it between 4 and $8 \mathrm{~Hz}$ [7]. The frequency and amplitude increase with age. The effects of essential tremor decrease when the patient drinks alcohol over a 30 minute period. Depending on its magnitude, this tremor does not usually require an aggressive medical treatment. It is possible that this type of tremor increases and, as a consequence, patients cannot carry out their daily activities. [2]. 


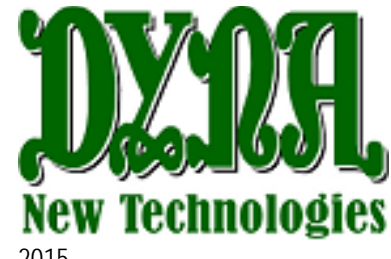

2015
A LOW COST SYSTEM FOR THE PREDIAGNOSIS OF THE HUMAN

TREMOR

María Luisa Pertegal-Felices, Antonio Jimeno-Morenilla, Francisco A. PujolLópez, Cristian Hernandez, Antonio Martínez-Alvarez
Tecnología Informática

Sensores

The cerebellar tremor is characterized by a spasmodic movement, and it is also created by a postural and a kinetic tremor [7]. It occurs when there is a voluntary movement, especially when the user requires precision in their movements. The amplitude of this tremor increases as the user approaches the target of his action. Some authors claim that this tremor has a variable and perpendicular oscillation to the voluntary movement. This tremor ends at the same time as the voluntary movement. Authors consider that this tremor is within the frequencies of 3-5 Hz [7] or 2-4 Hz [2]. Getting a finger to the nose is a typical test to assess this type of tremor.

\section{2.- Test and diagnosis}

Until now, there is no robust method to fully characterize the tremor of a patient. At diagnosis, physical tests are usually performed to determine its severity and origin. One of the first questions to be answered is whether the tremor happens mainly during action or if it occurs when at rest. The doctor must know about patient's relatives having the same problems and he/she will also emphasize the symmetry of the tremor. Blood and urine tests are often performed to detect if the cause of the tremor comes from a thyroid dysfunction or there are other causes involved. In addition, a series of physical tests such as holding an object, touching the tip of the nose or drawing geometrical figures are made. A diagram showing the diagnosis procedure is shown in Figure 1.

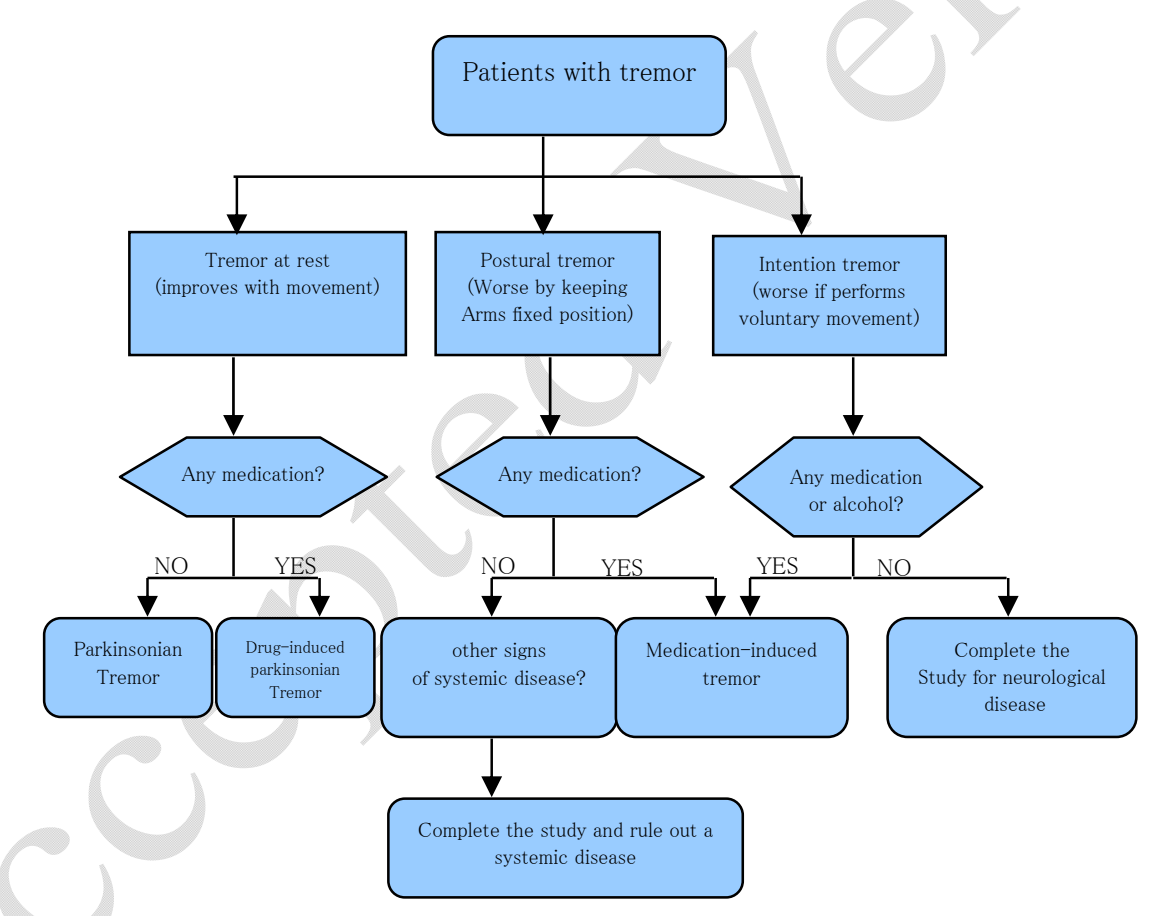

Figure 1. Diagnostic Procedure of tremor

\section{3.- Analysis of tremor signal}

The main problem when making a diagnosis is that the perception of the tremor is subjective. Therefore, two different doctors, when treating the same patient, could get to different conclusions. If the tremor is considered as a signal that oscillates, then its frequency and period can be calculated. Subsequently, there are many works that classify the tremor according to the amplitude and frequency values of the signal $[1,2,7,8]$. 


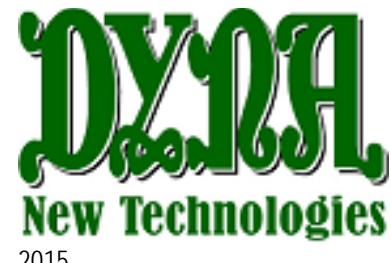

2015
A LOW COST SYSTEM FOR THE PREDIAGNOSIS OF THE HUMAN

TREMOR

From the point of view of a pre-diagnostic tool, the measures used by the doctors for the diagnoses of human tremor are the frequency and amplitude produced in the tests done by the patients (see Table 1):

Table 1. Tremor classification with respect to the frequency

\begin{tabular}{lll}
\hline Tremor Types & \multicolumn{2}{l}{ Frequencies $(\mathrm{Hz})$} \\
\hline Essential Tremor & {$[4.5-8]$} & {$[1,2]$} \\
& {$[4-8]$} & {$[7]$} \\
Parkinsonian Tremor & {$[3.5-6]$} & {$[1,2]$} \\
& {$[4-6]$} & {$[7]$} \\
Cerebellar Tremor & {$[3-5]$} & {$[7]$} \\
& {$[2-4]$} & {$[1,2]$} \\
\hline
\end{tabular}

After revising previous, related works, we have not found any method to accurately study the tremor signal using a lowcost device. For this reason, this research will aim to provide a tool by using a computer connected to a WiiMote ${ }^{\circledR}$ device that allows an expert to give accurate information to evaluate the tremor of a patient. This tool will include many of the techniques currently used by the scientific community.

This paper is organized as follows. In the first section the techniques used to characterize the tremor and the most common tests for this kind of patients are discussed. The second section describes the main filters used to analyze the tremor signal, as well as some metrics which characterize this signal. In the third section, the tool developed for the study of tremor, which makes use of analysis software connected to the WiiMote ${ }^{\circledR}$ device, is described. Finally, in Section 4 four case studies related to real cases of patients with different types of tremor and the analysis results showing the tool are shown. Finally, in Section 5 the main conclusions of this work are outlined.

\section{2.- FILTERS AND METRICS OF TREMOR ANALYSIS}

From the last section, it becomes clear that to achieve a reliable diagnosis, an accurate quantification of the tremor is required. Among others, there are currently two techniques mainly used in this field: the spectral analysis using either the Hilbert transform or the Fourier transform by applying the WFLC algorithm (Weighted Fourier Linear Combiner).

Eduardo Rocon et al. use a technique called Hilbert Analysis (HA) [11]. HA consists of two main components: The Empirical Mode Descomposition (EMD) and the Hilbert spectrum (HS). The Hilbert spectrum is subsequently used as a visualization tool that shows the change in energy and frequency of each movement. Rocon concludes that this tool allows quantifying the tremor. Furthermore, this technique may identify other involuntary movements.

The WFLC algorithm [10] allows modeling the tremor as a modulated sine wave with a time-varying frequency and amplitude. At every time step, error is measured between the tremor signal and the reference sine wave; depending on the error, frequency and amplitude of the reference sine wave are adjusted. The WFLC algorithm is as follows: 


$$
\begin{aligned}
& x_{r_{k}}=\left\{\begin{array}{l}
\sin \left(r \sum_{t=0}^{k} w_{0_{t}}\right), 1 \leq r \leq M \\
\cos \left((r-M) \sum_{t=0}^{k} w_{0_{t}}\right), M+1 \leq r \leq 2 M
\end{array}\right. \\
& \varepsilon_{k}=s_{k}^{\prime}-w_{k}^{T} \mathbf{x}_{k} \\
& w_{0_{k+1}}=w_{0_{k}}+2 \mu_{0} \varepsilon_{k} \sum_{i=1}^{M}\left(w_{i} x_{M+i}-w_{M+i} x_{i}\right) \\
& \mathbf{w}_{k+1}=w_{k}+2 \mu_{1} \mathbf{x}_{k} \varepsilon_{k}
\end{aligned}
$$

Here, $s_{k}$ is the raw signal, the weight filters are defined by $\mathbf{w}_{k}=\left[w_{1_{k}}, \cdots, w_{2 M_{k}}\right]^{T}, \mathbf{x}_{k}=\left[x_{1_{k}}, \cdots, x_{2 M_{k}}\right]^{T}$ is the model signal, $\varepsilon_{k}$ is the error, $M$ is the number of harmonics, $\mu_{0}$ and $\mu_{1}$ are adaptive gain parameters.

The WFLC algorithm is implemented as a gradient descent algorithm. It assumes that every signal is composed of other simpler signals in the form of sines and cosines, therefore, the algorithm starts with $M$ sine-cosine signals with amplitude and frequency values defined by default at the beginning of the algorithm. As the patient's tremor signal is received, these values change to follow as much as possible the patient's movements.

The WFLC is a robust and efficient method and it is especially useful in the analysis and diagnosis of tremor [10]. Consequently, this work will use WFLC to compute the principal components of the tremor signal.

\section{1.- Metrics}

Let us now define some metrics to validate the use of the WFLC algorithm. Thus, the Mean Square Error Tremor Movement (MSETM) is defined as follows.

$$
\operatorname{MSETM}=\frac{1}{N} \sum_{n=0}^{N} \sqrt{\left(T_{r}[n]-T_{o}[n]\right)^{2}}
$$

where $N$ is the number of samples, $T_{r}[n]$ is the reconstructed tremor signal and $T_{o}[n]$ is the original user's tremor signal. Thus, this metric expresses the error introduced when separating the tremor movements from the voluntary ones.

Accordingly, let us define a metric, the Mean Square Error Voluntary Movement (MSEVM), to measure the error introduced when separating the voluntary movements from the tremor ones, defined as:

$$
\operatorname{MSEVM}=\frac{1}{N} \sum_{n=0}^{N} \sqrt{\left(V_{r}[n]-V_{o}[n]\right)^{2}}
$$

where $V_{r}[n]$ is the real-time signal considered as a voluntary movement and $V_{0}[n]$ is the signal that represents the user's voluntary movement obtained offline, i.e., not in real time. This metric shows how the algorithm introduced errors in the calculation of the voluntary movement of the user. 

López, Cristian Hernandez, Antonio Martínez-Alvarez

We must remark that MSETM and MSEVM are not complementary metrics. Thus, as the post-processing algorithm is done offline and it is not ideal, then for the user's movement signal $X[n]$ it is accomplished that:

$$
X[n] \neq V_{0}[n]+T_{0}[n]
$$

The Filter Degree of Success (FDS) is a measure that relates the voluntary movement $V_{r}[n]$ and a guide signal that the user should follow, $G[n]$. This measure can also be expressed using squared error as follows:

$$
\mathrm{FDS}=\frac{1}{N} \sum_{n=0}^{N} \sqrt{\left(V_{r}[n]-G[n]\right)^{2}}
$$

Finally, the Filter efficiency (FE) is a metric that relates the voluntary signal obtained by the algorithm in real time against the real movement performed by the user. This way, we can measure the performance of the filter with respect to the original signal.

$$
\mathrm{FE}=\left(\frac{V_{r}}{M_{\text {real }}}\right)=10 \log _{10} \frac{P_{V_{r}}}{P_{M_{\text {real }}}}(d B)
$$

where $P_{V_{r}}$ is the power of the signal related to the voluntary movement and $P_{M_{\text {real }}}$ is the real movement done by the user. This metric will always give a negative number since the power of the signal from the actual movement should be greater than the signal after applying the filter. The power of a signal $x, P_{x}$, is defined as follows:

$$
P_{x}=|X[n]|^{2}=\lim \frac{1}{2 N+1} \sum_{n=-N}^{N}|x[n]|^{2}
$$

However, as the signal is finite, instead of using the concept of power, the energy of each signal will be employed. As a result, the energy of a signal $x, E_{x}$, is:

$$
E_{x}=\sum_{n=0}^{N} \mid X[n]^{2}
$$

From the expert's point of view, the most useful metric is FDS (5), since it provides an accurate measure of the completion of the diagnosis test. For this reason, this measure will be shown in the experiments. The rest of measures are used to fit the parameters of the WFLC filter.

To conclude this section, let us remark that the frequency and the amplitude mainly characterize the tremor. The frequency will classify the different types of possible tremors, as shown in Table 1 . The amplitude gives an approximate measure of the degree of the severity of the tremor. Consequently, the metrics proposed throughout this section will help an automatic system to evaluate both cues. 

López, Cristian Hernandez, Antonio Martínez-Alvarez

Tecnología Informática

Sensores

\section{3.- TOOL FOR THE TREMOR PREDIAGNOSIS}

\section{1.- Front-end application}

A java-based front-end application has been developed to give the expert the possibility of analyzing the frequencies and amplitudes that occurred during the patient's movement (see Figure 2). Using this interface, the expert can explore the signal and adjust it to different coefficients of filtering in order to obtain better results. In particular, the expert can choose study all movements did by user o selected a range of time for assessing a specific range of movements. The software shows the metrics defined in the previous section, and the frequency and amplitude distribution in order to distinguish anomalies or false positives.

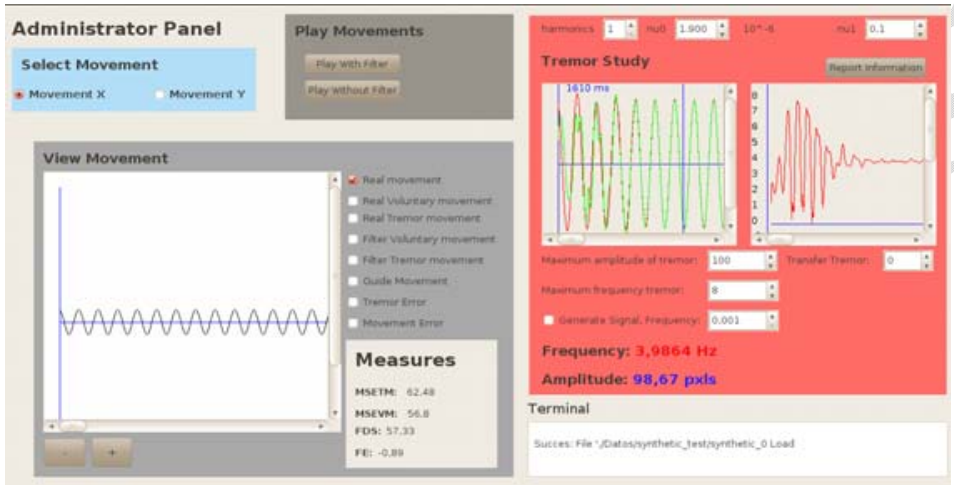

Figure 2. Prediagnosis control panel.

\section{2.- Capturing device}

In this investigation the Wiimote ${ }^{\circledR}$ remote controller from the Nintendo Wii ${ }^{\circledR}$ game console (see Figure 3 ) has been selected as the capturing device. It is a low-cost device (approx. 40€). This device consists of three accelerometers ADXL330 [12] (one per each Cartesian axis), and an infrared rays camera attached to the front. For the experiments, the device has been configured to replace the classical mouse, so when a user points to the screen, the cursor arrow follows the movements of the user.

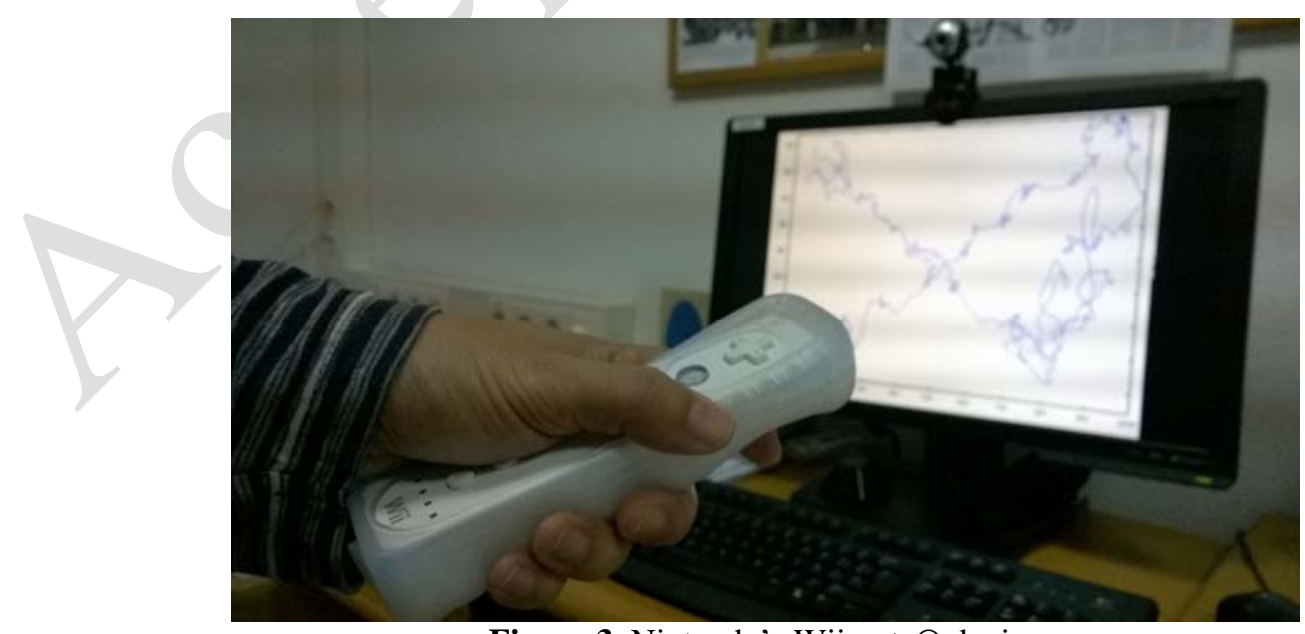

Figure 3. Nintendo’s Wiimote ${ }^{\circledR}$ device 


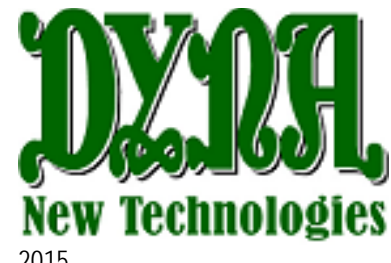

2015
A LOW COST SYSTEM FOR THE PREDIAGNOSIS OF THE HUMAN

TREMOR

María Luisa Pertegal-Felices, Antonio Jimeno-Morenilla, Francisco A. PujolLópez, Cristian Hernandez, Antonio Martínez-Alvarez
Tecnología Informática

Sensores

Wiimote provides discrete information about the cursor position at the screen. This information is send periodically to the computer. Therefore, if we consider the movement as a signal whose values are related with the position at the screen changing along the time, we may convert these values into a discrete signal [13].

The Wiimote computes the mouse position on the screen from the information received through its IR-camera. It has a resolution of $1024 \times 768$ pixels and a refresh rate of $100 \mathrm{~Hz}$. Using this system the position of the hand is determined when the user is located at a distance of $1 \mathrm{~m}$ from the camera with an average error of $1.2 \mathrm{~mm}$. This error increases to 1 $\mathrm{cm}$ when the distance is $2 \mathrm{~m}$ away [14]. The camera supports roll and yaw rotations of any kind, but is restricted to rotations of pitch in the range of $\pm 30^{\circ}$. The average error of estimating rotation angles is less than $1^{\circ}$ for distances less than $2 \mathrm{~m}$ from the camera. Regarding the accelerometers, the Wiimote gives acceleration values normalized by the gravity acceleration in the range $[-3 g,+3 g][15]$.

This method for obtaining positioning information adds some inaccuracies in the calculations. The infrared emitter may not be put near of the window or zones where there is a lot of light. The device has a source light vector and this source is ordered by light power. If the intensity of light from the source is decreased by interference from other light, such as solar, then affect the quality of the collected signal. For this reason, the light source station should not be placed next to large windows with plenty of light or near of mirrors or crystals that may confuse the infrared camera. Anyway, this disadvantage can be avoided using the extra information provided by the accelerometers.

The frequencies of human's tremor, as discussed above, are limited. That is, in most cases will be manifested in a range of frequencies that are between $0 \mathrm{~Hz}$ (ideal state) and the $12-14 \mathrm{~Hz}$ (a very severe tremor). WiiMote device, using the Java library, allows receiving samples at a rate of $10 \mathrm{~ms}$ (i.e. a sampling frequency of $100 \mathrm{~Hz}$ ). According to the NyquistShannon theorem, it is possible capture signals up to $50 \mathrm{~Hz}$. This frequency limit is enough to keep any details of the movements produced by patients with tremor.

From the stand point of the prediagnosis tool, for each test the capturing device will provide an array of positions regarding the movements made by patients.

\section{3.- Test design}

Tests are based on some of the physical test normally done at patients to diagnose tremor. The difficulty of tests is growing, so if a patient is unable to perform the test $i$ then the test $i+1$ will not be done, since it will require more precision.

Each test is repeated two or three times and they have a maximum duration of about 20 to 70 seconds.

\subsection{1.- Test 1}

The first test aims to target around a point just located at the center of the screen (see Figure 4). The point is fixed, not moving. The test takes about 20 seconds to perform. This test will show the postural tremor since it requires the patients to maintain a fixed position for a period of time. Therefore, we are promoting the development of essential tremor of a patient. This test will also highlight the Parkinsonian tremor that usually affects all the movements since the performance until the interruption of the movement. By the nature of this test is strange that the cerebellar tremor could appear. 


\section{DYSAT New Technologies}

María Luisa Pertegal-Felices, Antonio Jimeno-Morenilla, Francisco A. PujolLópez, Cristian Hernandez, Antonio Martínez-Alvarez
Tecnología Informática

Sensores

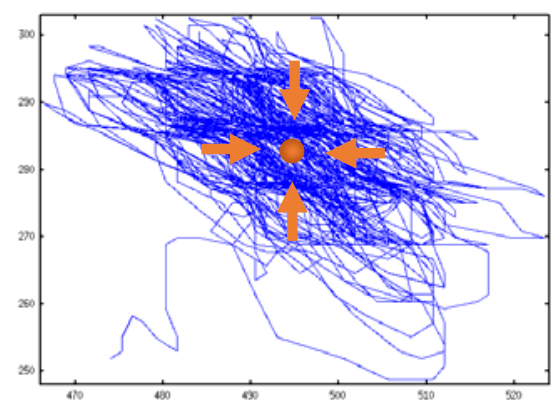

Figure 4. Sample of test 1

\subsection{2.- Test 2}

The second test consists of a movement from the left to the right of the screen that produces a horizontal movement (see Figure 5). This test involves a degree of precision low and their main task is to check the behavior of the arm when it performs horizontal movements. This test highlights the essential tremor during the entire test, except at the beginning and middle of the movement, when the lure changes the trend of the movement.

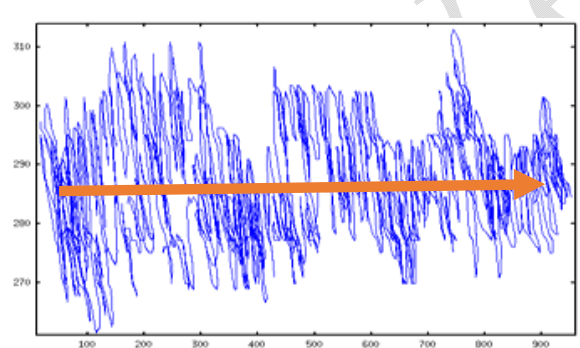

Figure 5. Sample of test 2.

\subsection{3.- Test 3}

The third test aims to draw an " $x$ " on the screen (see Figure 6). In this test, the horizontal and vertical movements are combined. In this way, it is possible obtaining information from both the upstream and the downstream movement. This test, like its predecessors, does not require a high level of precision but requires more accuracy that test 2.

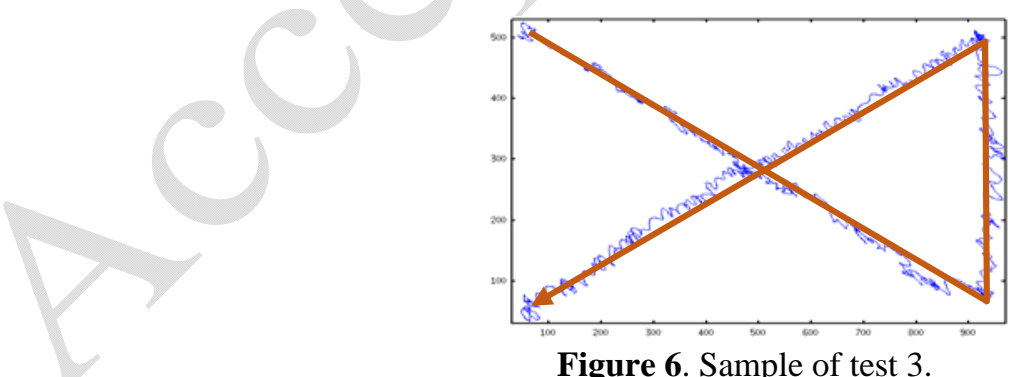

\subsection{4.- Test 4}

The fourth and last test aims to draw a square, providing information on the vertical movements performed by the patient's arm (see Figure 7). In this test, the decoy motion changes much more frequently than in the previous ones, this will imply a greater precision of movement and therefore the cerebellar tremor will stand out above the rest. 


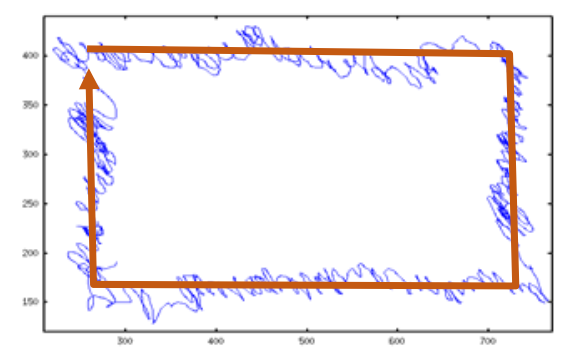

Figure 7. Sample of test 4.

\section{EXPERIMENTATION}

The tool will be tested using two users who suffer different tremor diseases. Patient 1 is a woman who is 79 years old and suffers an advanced parkinsonian tremor. The tremor occurs at rest and partially disabled her in some everyday situations. Tremor was observed in her head as a repetitive movement of type "no-no". Patient 2 is a woman who is 73 years old and she has a low tremor caused by the medication administered due to a thrombosis occurred two years ago.

Due to the increasing difficulty of tests, tests 1 and 2 will be applied to patient 1 (since she is unable to perform the rest of tests), and tests 3 and 4 will be performed by patient 2 (who suffers a lower tremor), since these tests require more precission.

The parameters chosen for the WFLC algorithm are:

$M=1$

$\mu_{0}=1,9 \cdot 10^{-3}$

$\mu_{1}=0.1$

where $\mathrm{M}$ is the number of harmonics used for follow the tremor signal, $\mu_{0}$ is the adaptive coefficient of frequency and $\mu_{1}$ is the adaptive coefficient of amplitude.

\section{1.- Test 1 on patient 1}

The first of test consist in hold the cursor in center of the screen. In the test, we search manifesting the essential tremor because the user has to maintain the posture for a period against gravity. The tremor that must appear is majority postural. The movements of the user are shown in Figure 8.

Usually, the movements made for the first user in the first test are:
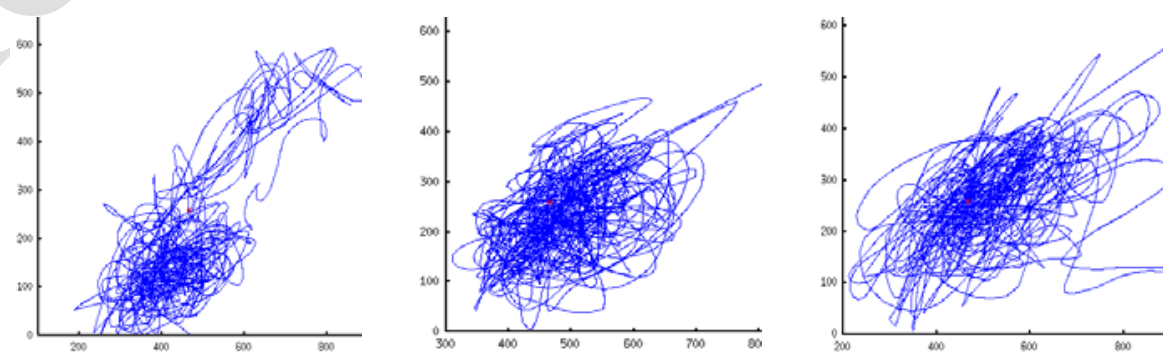

Figure 8. Movements for the first test. From left to right, samples 1, 2, and 3. 


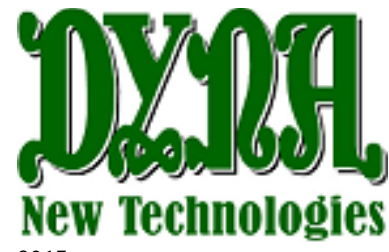

2015
A LOW COST SYSTEM FOR THE PREDIAGNOSIS OF THE HUMAN

TREMOR

María Luisa Pertegal-Felices, Antonio Jimeno-Morenilla, Francisco A. PujolLópez, Cristian Hernandez, Antonio Martínez-Alvarez
Tecnología Informática

Sensores

Each of the tests has been repeated three times to avoid wrong values. The results obtained in the first test are shown in tables 2 and 3.

Regarding the frequency results in table 2, an expert could conclude that there are a range of tremors whose frequencies vary from 1 to $3 \mathrm{~Hz}$. Furthermore, the amplitude results in table 3 show great oscillations, sometimes more than 100 pixels, indicating a severe tremor. These results highlight a Parkinsonian essential tremor produced when a fixed posture needs to be maintained.

Table 2. Frequecy distribution for test 1.

\begin{tabular}{crrrrrr}
\hline Hz & \multicolumn{2}{c}{ sample 1 } & \multicolumn{2}{c}{ sample 2 } & \multicolumn{2}{c}{ sample 3 } \\
& 6059 - movement & \multicolumn{2}{c}{ 10083 - movements } & \multicolumn{2}{c}{4933 - movements } \\
& number mov. & \multicolumn{1}{c}{$\%$} & number mov. & \multicolumn{1}{c}{$\%$} & number mov. & $\%$ \\
\hline$[0-1]$ & 2936 & $48,46 \%$ & 3955 & $39,22 \%$ & 14033 & $99,36 \%$ \\
{$[1-2]$} & 1483 & $24,48 \%$ & 3459 & $34,31 \%$ & 73 & $0,52 \%$ \\
{$[2-3]$} & 1499 & $24,74 \%$ & 2661 & $26,39 \%$ & 12 & $0,08 \%$ \\
{$[3-4]$} & 132 & $2,18 \%$ & 3 & $0,03 \%$ & 3 & $0,02 \%$ \\
{$[4-5]$} & 6 & $0,10 \%$ & 3 & $0,03 \%$ & 1 & $0,01 \%$ \\
{$[5-6]$} & 1 & $0,02 \%$ & 0 & $0,00 \%$ & 1 & $0.01 \%$ \\
{$[6-7]$} & 2 & $0,03 \%$ & 0 & $0,00 \%$ & 1 & $0.01 \%$ \\
{$[7-8]$} & 0 & $0,00 \%$ & 0 & $0,00 \%$ & 0 & $0,00 \%$ \\
\hline
\end{tabular}

Table 3. Amplitude distribution for test 1.

\begin{tabular}{|c|c|c|c|c|c|c|}
\hline \multirow[t]{2}{*}{ Pixels } & \multicolumn{2}{|c|}{$\begin{array}{c}\text { sample } 1 \\
6059 \text { - movements }\end{array}$} & \multicolumn{2}{|c|}{$\begin{array}{c}\text { sample } 2 \\
10083 \text { - movements }\end{array}$} & \multicolumn{2}{|c|}{$\begin{array}{c}\text { sample } 3 \\
4933 \text { - movements }\end{array}$} \\
\hline & number mov. & $\%$ & number mov. & $\%$ & Number mov. & $\%$ \\
\hline [0-10] & 2006 & $33.11 \%$ & 6690 & $66,35 \%$ & 10982 & $77,75 \%$ \\
\hline$[10-20]$ & 2428 & $40.07 \%$ & 455 & $4,51 \%$ & 1036 & $7,34 \%$ \\
\hline$[20-30]$ & 939 & $15,5 \%$ & 51 & $0,51 \%$ & 491 & $3,48 \%$ \\
\hline [30-40] & 381 & $6,29 \%$ & 32 & $0,32 \%$ & 100 & $0,71 \%$ \\
\hline [40-50] & 193 & $3,19 \%$ & 116 & $1,15 \%$ & 350 & $2,48 \%$ \\
\hline$[50-60]$ & 70 & $1,16 \%$ & 188 & $1,86 \%$ & 307 & $2,17 \%$ \\
\hline [60-70] & 6 & $0,10 \%$ & 13 & $0,13 \%$ & 209 & $1,48 \%$ \\
\hline$[70-80]$ & 3 & $0,05 \%$ & 290 & $2,88 \%$ & 221 & $1,56 \%$ \\
\hline [80-90] & 2 & $0,03 \%$ & 374 & $3,71 \%$ & 126 & $0,89 \%$ \\
\hline [90-100] & 1 & $0,02 \%$ & 490 & $4,86 \%$ & 117 & $0,83 \%$ \\
\hline [100-110] & 4 & $0,07 \%$ & 389 & $3,86 \%$ & 116 & $0,82 \%$ \\
\hline [110-120] & 8 & $0,13 \%$ & 204 & $2,02 \%$ & 28 & $0,20 \%$ \\
\hline [120-130] & 9 & $0,15 \%$ & 407 & $4,04 \%$ & 17 & $0,12 \%$ \\
\hline [130-140] & 1 & $0,02 \%$ & 224 & $2,22 \%$ & 7 & $0,05 \%$ \\
\hline [140-150] & 2 & $0,03 \%$ & 133 & $1,32 \%$ & 10 & $0,07 \%$ \\
\hline [150-160] & 4 & $0,07 \%$ & 18 & $0,18 \%$ & 1 & $0,01 \%$ \\
\hline [160-170] & 2 & $0,03 \%$ & 1 & $0,01 \%$ & 3 & $0,02 \%$ \\
\hline$[170-180]$ & 0 & $0,00 \%$ & 2 & $0,02 \%$ & 3 & $0,02 \%$ \\
\hline [180-190] & 0 & $0,00 \%$ & 2 & $0,02 \%$ & 0 & $0 \%$ \\
\hline [190-210] & 0 & $0,00 \%$ & 4 & $0,04 \%$ & 0 & $0 \%$ \\
\hline [210-220] & 0 & $0,00 \%$ & 0 & $0 \%$ & 0 & $0 \%$ \\
\hline
\end{tabular}


Table 4 shows the filter degree of success (FDS) for the experiment. This metric represents the absolute error committed between voluntary movements obtained from the filter against the guide. Therefore, this metric indicates how accurate the user has been with respect to the guide. We conclude that the second one repeat had better follow by user. This may also be contrasted with the pictures showed in figure 1.

Table 4. Filter degree of success.

\begin{tabular}{cccc}
\hline & sample 1 & sample 2 & sample 3 \\
\hline FDS & 97,87 & 60,09 & 98,82 \\
\hline
\end{tabular}

\section{2.- Test 2 on patient 1}

In the second test, the patient moves the cursor from left to right following the guide through the screen. This time, the attention will be focused on the movements in the y-axis. The Figure 9 shows the movements made by patient 1 .
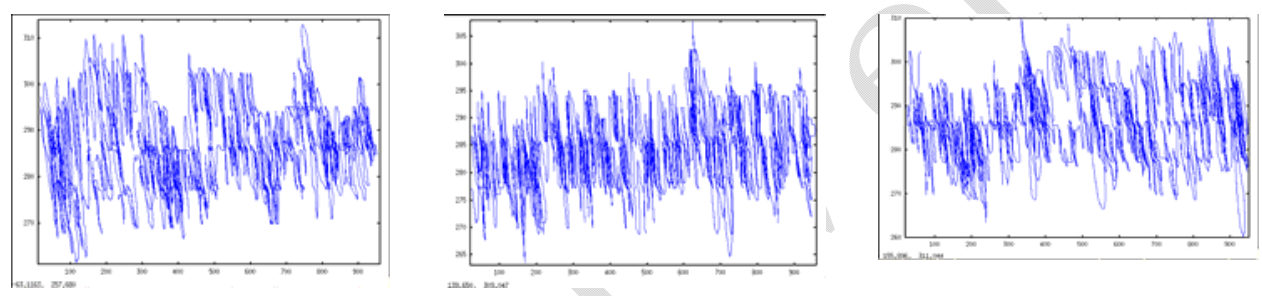

Figure 9. Movements for the second test. From left to right, samples 1, 2, and 3.

Table 5. Frequecy distribution for test 2.

\begin{tabular}{|c|c|c|c|c|c|c|}
\hline \multirow[t]{2}{*}{$\mathrm{Hz}$} & \multicolumn{2}{|c|}{$\begin{array}{c}\text { sample } 1 \\
12094 \text { - movements }\end{array}$} & \multicolumn{2}{|c|}{$\begin{array}{c}\text { sample } 2 \\
15048 \text { - movements }\end{array}$} & \multicolumn{2}{|c|}{$\begin{array}{c}\text { sample } 3 \\
18125 \text { - movements }\end{array}$} \\
\hline & number mov. & $\%$ & number mov. & $\%$ & number mov. & $\%$ \\
\hline$[0-1]$ & 30 & $0,25 \%$ & 31 & $0,21 \%$ & 37 & $0,20 \%$ \\
\hline [1-2] & 1628 & $13,46 \%$ & 90 & $0,60 \%$ & 27 & $0,15 \%$ \\
\hline [2-3] & 10432 & $86,26 \%$ & 14917 & $99,13 \%$ & 18061 & $99,65 \%$ \\
\hline [3-4] & 4 & $0,03 \%$ & 3 & $0,02 \%$ & 0 & 0 \\
\hline [4-5] & 0 & 0 & 7 & $0,05 \%$ & 0 & 0 \\
\hline [5-6] & 0 & 0 & 0 & 0 & 0 & 0 \\
\hline
\end{tabular}

Tables 5 and 6 show the test results. From the amplitude distribution data (table 6), the tremor has significantly decreased with respect to the previous test. From the expert's point of view, this result confirms the Parkinsonian nature of the tremor, which decreases when performing a controlled movement. Moreover, the frequency distribution data (table 5) are mainly found in the range [2-3] Hz.

Table 6. Frequecy distribution for test 2.

\begin{tabular}{lcrrrrr}
\hline \multirow{2}{*}{ Pixels } & \multicolumn{2}{c}{ sample 1 } & \multicolumn{2}{c}{ sample 2 } & \multicolumn{2}{c}{ sample 3 } \\
& \multicolumn{1}{c}{12094 - movements } & \multicolumn{2}{c}{15048 - movements } & \multicolumn{2}{c}{18125 - movements } \\
& number mov. & $\%$ & number mov. & number mov. & $\%$ \\
\hline$[0-10]$ & 11983 & $99,08 \%$ & 14946 & $99,32 \%$ & 18009 & $99,36 \%$ \\
{$[10-20]$} & 47 & $0,39 \%$ & 27 & $0,18 \%$ & 51 & $0,28 \%$ \\
& & & & &
\end{tabular}



López, Cristian Hernandez, Antonio Martínez-Alvarez

\begin{tabular}{lrrrrrr}
\hline$[20-30]$ & 13 & $0,11 \%$ & 7 & $0,05 \%$ & 17 & $0,09 \%$ \\
{$[30-40]$} & 9 & $0,07 \%$ & 19 & $0,13 \%$ & 25 & $0,14 \%$ \\
{$[40-50]$} & 12 & $0,10 \%$ & 11 & $0,07 \%$ & 8 & $0,04 \%$ \\
{$[50-60]$} & 17 & $0,14 \%$ & 21 & $0,14 \%$ & 2 & $0,01 \%$ \\
{$[60-70]$} & 2 & $0,02 \%$ & 6 & $0,04 \%$ & 1 & $0,01 \%$ \\
{$[70-80]$} & 2 & $0,02 \%$ & 2 & $0,01 \%$ & 2 & $0,01 \%$ \\
{$[80-90]$} & 3 & $0,02 \%$ & 3 & $0,02 \%$ & 2 & $0,01 \%$ \\
{$[90-100]$} & 6 & $0,05 \%$ & 6 & $0,04 \%$ & 3 & $0,02 \%$ \\
{$[100-110]$} & 0 & 0 & 0 & 0 & 5 & $0,03 \%$ \\
\hline
\end{tabular}

Table 7. Filter degree of success.

\begin{tabular}{cccc}
\hline & First one & Second one & Third one \\
\hline FDS & 25,03 & 26,84 & 27,73 \\
\hline
\end{tabular}

Table 7 shows the FDS metric for this experiment. Due to the fact of the lower tremor amplitude, the error has considerably decreased in the three samples regarding the previous experiment.

\section{3.- Test 3 on patient 2}

The third test involves painting a cross on screen. Patient 2 started painting in upper left corner on the screen and ended in the bottom left corner on the screen. The drawings are showed in Figure 10. Two samples were needed for performing the test.

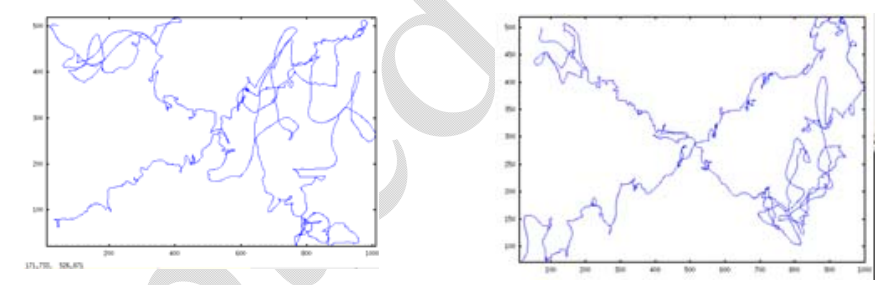

Figure 10. Movements for the third test. From left to right, samples 1, and 2.

\begin{tabular}{crrrr}
\multicolumn{5}{c}{ Table 8. Frequency distribution for test 3. } \\
\hline Hz & \multicolumn{2}{c}{ sample 1 } & \multicolumn{2}{c}{ sample 2 } \\
& $\begin{array}{c}600 \text { movements } \\
\text { number }\end{array}$ & $\%$ & 2027 movements \\
& number & $\%$ \\
\hline$[0-1]$ & 89 & $13,48 \%$ & 85 & $4,19 \%$ \\
{$[1-2]$} & 209 & $31,67 \%$ & 828 & $40,85 \%$ \\
{$[2-3]$} & 357 & $54,09 \%$ & 1114 & $54,96 \%$ \\
{$[3-4]$} & 5 & $0.76 \%$ & 0 & $0,00 \%$ \\
{$[4-5]$} & 0 & $0,00 \%$ & 0 & $0,00 \%$ \\
{$[5-6]$} & 0 & $0,00 \%$ & 0 & $0,00 \%$ \\
\hline
\end{tabular}

Table 9. Amplitude distribution for test 3.

\begin{tabular}{ccccc}
\hline pixels & \multicolumn{2}{c}{ sample 1 } & \multicolumn{2}{c}{ sample 2 } \\
& \multicolumn{2}{c}{660} & movements & \multicolumn{2}{c}{2027 movements } \\
& number & $\%$ & number & $\%$ \\
\hline$[0-10]$ & 366 & $55,45 \%$ & 1739 & $85,79 \%$
\end{tabular}



López, Cristian Hernandez, Antonio Martínez-Alvarez

Tecnología Informática Sensores

\begin{tabular}{rrrrr}
\hline$[10-20]$ & 192 & $29,09 \%$ & 288 & $14,21 \%$ \\
{$[20-30]$} & 35 & $5,30 \%$ & 0 & $0,00 \%$ \\
{$[30-40]$} & 41 & $6,21 \%$ & 0 & $0,00 \%$ \\
{$[40-50]$} & 10 & $1,52 \%$ & 0 & $0,00 \%$ \\
{$[50-60]$} & 16 & $2,42 \%$ & 0 & $0,00 \%$ \\
{$[60-70]$} & 0 & $0,00 \%$ & 0 & $0,00 \%$ \\
\hline
\end{tabular}

The FDS showed in table 10, clearly reflects the best behavior of user in sample 2 as showed in figure 4.

Table 10. Filter degree of success.

\begin{tabular}{ll}
\hline & FDS \\
\hline First one & 63,18 \\
Second one & 41,93 \\
\hline
\end{tabular}

From the amplitude data (table 9), the tremor has not a high intensity, since the movements are mostly below 10 pixels. Furthermore, the frequency values are mainly in the range [1-3] Hz. As a result, a cerebellar tremor may be diagnosed. However, test 4 will be performed to confirm the diagnosis.

\section{4.- Test 4 on patient 2}

The fourth test consists of drawing a rectangle on the screen following the guide. The movements of patient 2 are showed on Figure 11 for every sample.

The results of this test are very similar to the ones in test 3 . Table 11 shows a higher concentration in the range [2-3] Hz (more than 99\%). Thus, the tremor is likely to be of cerebellar type. The tremor severity is low. Table 12 shows that oscillations are mostly under 10 pixels. However, the expert will take a final decision based on other clinical tests.

Table 11. Frequency distribution for test 4.

\begin{tabular}{rrrrrrr}
\hline Hz & \multicolumn{2}{c}{ sample 1 } & \multicolumn{2}{c}{ sample 2 } & \multicolumn{2}{c}{ sample 3 } \\
& 6000 - movements & \multicolumn{2}{c}{6000 - movements } & \multicolumn{2}{c}{6000 - movements } \\
& Number Mov. & $\%$ & Number Mov. & $\%$ & Number Mov. & $\%$ \\
\hline$[0-1]$ & 17 & $0,28 \%$ & 57 & $0,95 \%$ & 18 & $0,30 \%$ \\
{$[1-2]$} & 17 & $0,28 \%$ & 0 & 0 & 5 & $0,08 \%$ \\
{$[2-3]$} & 5966 & $99,43 \%$ & 5943 & $99,05 \%$ & 5977 & $99,62 \%$ \\
{$[3-4]$} & 0 & $0,00 \%$ & 0 & 0 & 0 & $0,00 \%$ \\
{$[4-5]$} & 0 & $0,00 \%$ & 0 & 0 & 0 & $0,00 \%$ \\
{$[5-6]$} & 0 & $0,00 \%$ & 0 & 0 & 0 & $0,00 \%$ \\
\hline
\end{tabular}

Table 12. Amplitude distribution for test 4.

\begin{tabular}{lrrrrrr}
\hline Pixels & \multicolumn{2}{c}{ sample 1 } & \multicolumn{2}{c}{ sample 2 } & \multicolumn{2}{c}{ sample 3 } \\
& \multicolumn{2}{c}{6000 - movements } & \multicolumn{2}{c}{6000 - movements } & \multicolumn{2}{c}{6000 - movements } \\
& number mov. & \multicolumn{1}{c}{$\%$} & number mov. & $\%$ & number mov. & $\%$ \\
\hline$[0-10]$ & 5909 & $98,48 \%$ & 5942 & $99,03 \%$ & 5912 & $98,53 \%$ \\
{$[10-20]$} & 41 & $0,68 \%$ & 32 & $0,53 \%$ & 31 & $0,52 \%$ \\
{$[20-30]$} & 15 & $0,25 \%$ & 11 & $0,18 \%$ & 36 & $0,60 \%$ \\
{$[30-40]$} & 22 & $0,37 \%$ & 2 & $0,03 \%$ & 8 & $0,13 \%$
\end{tabular}



López, Cristian Hernandez, Antonio Martínez-Alvarez

Tecnología Informática

Sensores

\begin{tabular}{lllllll}
\hline$[40-50]$ & 3 & $0,05 \%$ & 4 & $0,07 \%$ & 2 & $0,03 \%$ \\
{$[50-60]$} & 4 & $0,07 \%$ & 5 & $0,08 \%$ & 4 & $0,07 \%$ \\
{$[60-70]$} & 6 & $0,10 \%$ & 4 & $0,07 \%$ & 7 & $0,12 \%$ \\
{$[70-80]$} & 0 & $0,00 \%$ & 0 & $0,00 \%$ & 0 & $0,00 \%$ \\
\hline
\end{tabular}

The FDS showed in table 13, shows a similar low error for the three samples which agrees with the low tremor severity of this patient.

Table 13. Filter degree of success.

\begin{tabular}{cccc}
\hline & sample 1 & sample 2 & sample 3 \\
\hline FDS & 27,02 & 28,85 & 30,02 \\
\hline
\end{tabular}
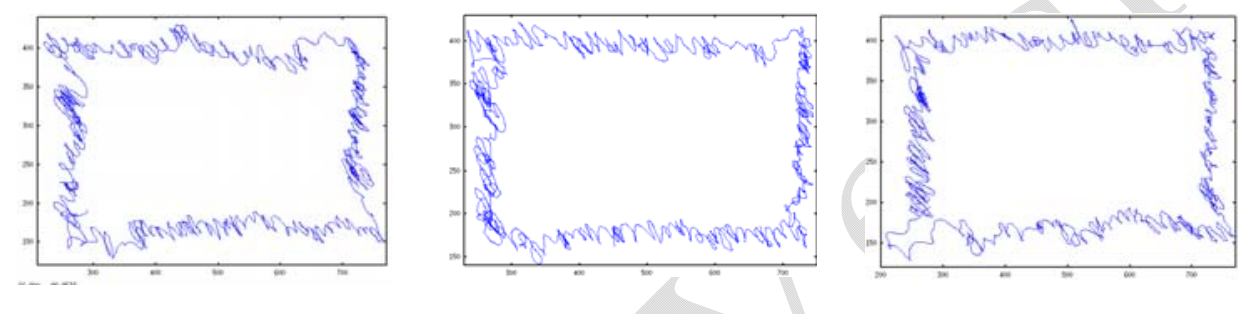

Figure 11. Movements for the fourth test. From left to right, samples 1, 2, and 3.

\section{5.- CONCLUSIONS}

In this paper, a new tool for the prediagnosis of the human tremor is presented. This tool incorporates techniques of WFLC filters and different metrics in order to help the doctor make a faster diagnosis of the human tremor.

Regarding to the hardware, a popular and low cost device $(<\$ 40)$ is proposed: the remote control of the Nintendo Wii ${ }^{\circ}$ video game console called Wiimote ${ }^{\circledR}$. In addition, a Java-based $\AA$ front-end has been implemented offering to the expert useful metrics and accurate information about the movements of the patient. The algorithm allows computing the main factors of the human tremor accurately using WFLC filters.

Two real cases have been tested using the algorithms developed in this investigation. The patients suffered from different tremor severities, and the components of amplitude and frequency were computed using a series of tests. These additional measures will help the experts to make better diagnoses allowing them to focus on specific stages of the test or get an overview of these tests. From the experiments, we stated that not all tests are valid for every patient to give a diagnosis. Guided by years of experience, the expert will decide which test or set of tests are the most appropriate for a patient.

Future studies will be focused on adding more functionality to the application. For example, more types of tests could be designed, such as spirals or discontinuous movements. It will be possible to associate data not only to time, but also to some specific events, such as changes of direction, rest, spasmodic movement analysis, and so on. Artificial intelligence techniques will be also explored in order to provide self-adaptation of filter parameters and give a more complex interpretation of results to the expert.

The Wiimote provides a reasonable accuracy at low cost. However, if the precision of the system needs to be increased, a more accurate device must replace the Wiimote. As a future work, we propose to use simple haptic devices, such as PHANToM ${ }^{\circledR}[16]$, in order to improve the precision of our current system. 

López, Cristian Hernandez, Antonio Martínez-Alvarez

Tecnología Informática Sensores

\section{6.- REFERENCES}

1. Gresty, M., \& Buckwell, D. (1990). Spectral analysis of tremor: understanding the results. Journal of Neurology, Neurosurgery \& Psychiatry, 53(11), 976-981.

2. Eduardo R. L. (2006). Active reduction of the arms' pathological tremor using robotic exoskeletons. PhD dissertation (in Spanish). Polytechnic University of Madrid.

3. McAuley, J. H., \& Marsden, C. D. (2000). Physiological and pathological tremors and rhythmic central motor control. Brain, 123(8), 1545-1567.

4. Eberhart, R. C., \& Hu, X. (1999). Human tremor analysis using particle swarm optimization. In Evolutionary Computation, 1999. CEC 99. Proceedings of the 1999 Congress on (Vol. 3). IEEE.

5. Elble, R. J., and Koller W. C., (1990). Tremor. The Johns Hopkins University Press Baltimore, MD.

6. Marshall, J., \& Schnieden, H. (1966). Effect of adrenaline, noradrenaline, atropine, and nicotine on some types of human tremor. Journal of neurology, neurosurgery, and psychiatry, 29(3), 214.

7. Anouti, A., \& Koller, W. C. (1995). Tremor disorders. Diagnosis and management. Western journal of medicine, 162(6), 510.

8. Manto, M., Topping, M., Soede, M., Sanchez-Lacuesta, J., Harwin, W., Pons, J., ... \& Normie, L. (2003). Dynamically responsive intervention for tremor suppression. Engineering in Medicine and Biology Magazine, IEEE, 22(3), 120-132.

9. Louis, E. D., Ford, B., Lee, H., Andrews, H., \& Cameron, G. (1998). Diagnostic criteria for essential tremor: a population perspective. Archives of neurology, 55(6), 823-828.

10. Riviere, C. N., Rader, R. S., \& Thakor, N. V. (1998). Adaptive cancelling of physiological tremor for improved precision in microsurgery. Biomedical Engineering, IEEE Transactions on, 45(7), 839-846.

11. Rocon, E., Ruíz, A., Bueno, L., Ceres, R., Calderón, L., \& Pons, J. L. (2003). A new sensor for the measure of the tremor using gyroscopes. (in Spanish) Proceedings of the XXIV Conference on Robotics (CEA-IFAC).

12. WiiMote device technical data, http://wiibrew.org/wiki/Wiimote, February, (2011)

13. Deutsch, J. E., Borbely, M., Filler, J., Huhn, K., \& Guarrera-Bowlby, P. (2008). Use of a lowcost, commercially available gaming console (Wii) for rehabilitation of an adolescent with cerebral palsy. Physical therapy, 88(10), 1196-1207.

14. e Amici, S., Sanna, A., Lamberti, F., \& Pralio, B. (2010). A Wii remote-based infrared-optical tracking system. Entertainment Computing, 1(3), 119-124.

15. Lee, J.C. (2008). Hacking the Nintendo Wii Remote. IEEE Pervasive Computing, 7(3), 39-45.

16. Kheddar, A., Gourishankar, V., \& Evrard, P. (2008). A PHANTOM® Device with 6DOF Force Feedback and Sensing Capabilities. In Haptics: Perception, Devices and Scenarios (pp. 146-150). Springer Berlin Heidelberg. 